Article

\title{
Contexts and Interconnections: A Conjunctural Approach to Territorial Cohesion
}

\author{
Maja de Neergaard ${ }^{1, *}$, Mia Arp Fallov ${ }^{2}$, Rikke Skovgaard Nielsen ${ }^{1}$ and Anja Jørgensen ${ }^{2}$ \\ ${ }^{1}$ Department of the Built Environment, Aalborg University, 2450 Copenhagen, Denmark; \\ E-Mails: mlsdn@build.aau.dk (M.D.N), risn@build.aau.dk (R.S.N.) \\ 2 Department of Sociology and Social Work, Aalborg University, 9220 Aalborg, Denmark; \\ E-Mails: fallov@socsci.aau.dk (M.A.F.), anjaj@socsci.aau.dk (A.J.) \\ * Corresponding author
}

Submitted: 16 June 2020 | Accepted: 28 September 2020 | Published: 3 December 2020

\begin{abstract}
This article contributes to current debates around EU policy on territorial cohesion and its place-based approaches. Based on substantial empirical research in seven member countries in an on-going EU Horizon 2020 project, the article develops a conjunctural approach based on Doreen Massey's conceptualisation of place to provide insight into how local development functions in spatial and temporal dimensions. One of the main objectives of the case studies is to compare policy programmes and practices that seek to alleviate territorial inequality and generate economic growth and territorial cohesion. In such a comparison, the issue of conflating and rescaling administrative territorial units and boundaries demands particular attention. Administrative boundaries do not necessarily reflect the complexity and interconnections between policy actors, businesses, and local communities. Local specificities make it difficult to compare the local political room for manoeuvre due to different administrative principles, unequal degrees of devolution of competences or differences in constitutions, e.g., federal states versus unity states. In this article, we argue that, faced with an analysis of highly diverse cases, a conjunctural analytical approach can help to capture and unpack some of the places' complexities and regional interconnections and be a useful supplement to more conventional comparisons of more similar places. Through two examples, the article discusses what the application of this conjunctural approach means in practice, how it helped shape our understanding of how differently and how it can be further developed to accommodate place-based approaches to researching territorial cohesion.
\end{abstract}

\section{Keywords}

conjunctures; place-based approach; territorial cohesion; territorial inequality

\section{Issue}

This article is part of the issue "Cohesion in the Local Context: Reconciling the Territorial, Economic and Social Dimensions," edited by Anja Jørgensen (Aalborg University, Denmark), Mia Arp Fallov (Aalborg University, Denmark), Rikke Skovgaard Nielsen (Aalborg University, Denmark), Hans Thor Andersen (Aalborg University, Denmark) and Maja de Neergaard (Aalborg University, Denmark).

(C) 2020 by the authors; licensee Cogitatio (Lisbon, Portugal). This article is licensed under a Creative Commons Attribution 4.0 International License (CC BY).

\section{Introduction}

During the past decade, EU cohesion policy has experienced the development of what has been called a 'place-based approach' in its efforts to bridge economic, social and territorial cohesion (Abrahams, 2014; Atkinson \& Zimmermann, 2018; Faludi, 2006). The place- based approach seeks to grapple with the overlapping, sometimes conflating and, in any case, enmeshed flows of initiatives and actors, policies and finance at different administrative and governance levels. In analysing variations between very different EU countries, the article addresses the need for an analytical perspective which can encompass the multiple variations 
between places. The article draws on examples from the analysis and evaluation of local cohesion policy initiatives in selected case studies from the ongoing Horizon 2020 project "Inequality, Urbanization and Territorial Cohesion: Developing the European Social Model of Economic Growth and Democratic Capacity" (COHSMO). While not in any straightforward manner, these initiatives have developed within the framework of EU cohesion policy and the place-based approach. However, in assessing and analysing their composition and impact there are interesting similarities and differences between the individual places that are easily overlooked. The project represents seven very different member countries-the UK (the grant was given ahead of Brexit), Austria, Italy, Greece, Poland, Lithuania and Denmark. Within each country, three case studies have been done in small, middle-sized and large cities (see Section 4 below). Meanwhile, as the project developed some interesting parallels, contrasts between some of the individual cases were observed but not easily addressed within the established research design. In stretching over very diverse cases, focusing the analysis on what we might call 'conventional similarities' is easily favoured. But in some instances between the very diverse cases-like the examples taken up here-we discover manifestations of places that are interesting to compare because of how they correspond to the same developmental dynamics (and challenges) on the one hand, while on the other hand comprising of contextspecific territorial differences and similarities that are not meaningfully unified or put into a singular explanation. To better capture and unpack these complex and interconnected relations, the article revisits Doreen Massey's $(1991,2005)$ notion of place as 'throwntogethernes,' and picks up some of the literature that follows her relational approach to place and continues the conversation of conjunctures. The shift in cohesion policy towards the place-based approach can be said to represent an understanding of places as multiple and overlapping, and therefore as corresponding with the relational view. As an analytical approach, tracing the conjuncture(s) will supplement the analysis of possible mechanisms and explanations drawn from comparing administratively defined geographical units by giving greater emphasis on the importance and constitutive role of geographical, historical and political interconnections.

While the article draws on Massey's work, we want to acknowledge that there are other bodies of literature that have taken similar grips with theorising key territorial concepts and shown interest in relational thinking. For instance, at about the same time as the interest in place gained momentum in the 1980s, a similar development took place around the notion of 'locality.' At a time of de-industrialisation and economic restructuring, there was a need for new ways of understanding regional development. In many ways, the discussion revolved around the same overall questions of the impact and nature of 'spatial' vis-à-vis 'social' forces, the recognition of the global in the local and vice versa, and the relationships between spatial scales (Cooke, 1990; Savage \& Duncan, 1990; for a relatively recent contribution with a summary of earlier literature see Jones \& Woods, 2013).

The article begins by outlining the recent emphasis in the EU on a place-based approach to understanding territorial cohesion emphasising the proclaimed need stated in the literature for more focus on contextual conditions. The article then re-visits some of the literature that accommodated the above-mentioned 'turn' towards a relational understanding of place. Following this, we try to develop this analytical framework through two examples from the COHSMO project. In the final section of the article, we discuss the implications of the suggested analytical framework; focusing on the knowledge gained from conjunctural analysis.

\section{Territorial Cohesion and the Place-Based Approach}

Over the past decade, EU cohesion policy has increasingly moved towards a place-based approach to improve the quality of regional development strategies (Barca, 2009). The core idea is that each region has a (sometimes not fully-developed) potential that can be realised through a mix of endogenous and exogenous resources. As argued by Barca, McCann, and Rodríguez-Pose (2012, p. 140), "the place-based approach assumes that geographical context really matters, whereby context here is understood in terms of its social, cultural, and institutional characteristics" (p. 140). The Barca Report also argues that "apparently, space-neutral policies will always have explicit spatial effects, many of which will undermine the aims of the policy itself unless its spatial effects are explicitly taken into consideration" (Barca, 2009, p. 140). As far as the endogenous dimension is concerned, Barca (2009, p. 22) clearly acknowledges that among the relevant preconditions for effective local development policies "both formal and informal institutions are a prerequisite for a place to make full use of its potential." Among such institutions, Barca lists the agency of individuals, social capital, trust, democratic participation in decision-making and institutional capacity while at the same time warns that "the problem with all these prerequisites is that they do not arise easily and are highly path-dependent" (Barca, 2009, p. 22).

In 2011, after the publication of Europe 2020 (EU's ten-year strategy from 2010), another key publication emerged that was prepared on request of the European Council for advice on how to strengthen the territorial dimension of EU cohesion policy and the Europe 2020-strategy: the known Böhme Report. The report contains a review of the most important initiatives and publications made in the field of territorial cohesion under the auspices of the EU (Böhme, Doucet, Komornicki, Zaucha, \& Świątek, 2011). The review shows that few attempts have been made to integrate territorial perspectives within developmental policies and argues that the territorial approach of the Europe 2020-strategy is 
"blurred" and "territorially blind" (Böhme et al., 2011, p. 17). The lack of territorial focus is ascribed to a more general "mental and institutional" lack of contact between the fields of territorial development and socioeconomic growth (Böhme et al., 2011, p. 21) and the report proposes to connect place-based policies within the framework of EU cohesion policy.

The reason for this territorial blindness, the report argues, is that the strategy operates with a much too narrow understanding of territoriality as this impact is primarily dealt with as a matter of transport and infrastructure. In the Territorial Agenda 2020 (which is part of the Europe 2020 strategy), which focuses on smart, inclusive and sustainable growth, there is no description or analysis of the impacts of the territorial factors. The Böhme Report emphasises that the proper 'territorial keys' enabling the desired development are missing. Among these keys are territorial capacities/endowments/assets and city networking. Territory-bound factors and local milieus are mentioned, but it is only sparsely clarified what these factors consist of and how they are conceptualised. Especially concerning territorial capacities/endowments/assets, the Böhme Report mentions alternative indicators such as civic society (NGO active share of the population, election turnout), social capital, regionalised educational attainment and cultural networks/routes as factors that can be used as a preliminary platform to comprehend places as socially and culturally different. These place-bound social and cultural differences have to be taken into account for territorial policies to be effective. A general point is that the different keys will act in different ways in different countries and that the scales and levels in which these keys are used are decisive for the outcomes. Indeed, once applied at different scales, in some cases the outcomes can even be contradictory (Böhme et al., 2011).

While the notion of territorial cohesion has become mobilised in several policy documents during the past decade, there remains little consensus in the academic literature on what it actually means. Also, the understandings of place and geographic scale concerning the questions of territorial cohesion are unclear (Atkinson \& Zimmermann, 2018). Moreover, despite several rounds of EU cohesion policies, and a range of spatial planning reports from the ESPON-projects, there is a lack of understanding of what territorial cohesion 'does' and how it relates to what goes on in particular, diverse places (Abrahams, 2014). As Faludi (2016) argues, one of the reasons why territorial cohesion remains a fuzzy and unclear concept is that our understanding of territorialism is stuck in a tradition of spatial order and linearity:

Territorialism - painting the image of a well-ordered world of boxes stacked into boxes, presumably until the globe, too, is safely cocooned in one super-boxis an illusion and an inhumane one to boot. It puts the box, in particular, that of the nation-state, above the human being. (Faludi, 2016, p. 80)
Instead of territorialism, Faludi argues for a different set of spatial metaphors viewing Europe as an archipelago in a sea of malleable functional regions in which the different spatial units change in interaction with the context of the sea. His arguments point to the importance of operating with a diverse conceptualisation of place, and of adjusting conventional thinking of fixed scales and clear boundaries to adjust analysis and policy implementation to human life in and through places. Accordingly, we must strengthen our understanding of the highly contextual place-dynamics that influence the formations of territorial inequality and cohesion. Certainly, political, economic and governmental relations are part of the reason behind these differences, but local, social interaction and historical, symbolic and traditional attachment to local communities and places play an important, but often ignored, role in causing these differences.

\section{Revisiting Place as 'Throwntogetherness' and the Notion of 'Conjunctures'}

Having outlined, in brief, the development around territoriality and place in EU cohesion policy, and the call in the literature for greater context-sensitivity to deepen our analysis of the drivers in regional development, this section turns to the theoretical backdrop for the analytic approach (or lens, one might say) that we argue for here. In geography, the notion of place has come to represent a thoroughly theorised (and complex) concept that engages convincingly with relationality and structural power while upholding a sense of particularity and open-endedness. It addresses the way different territorial 'layers,' in lack of a better expression, are mutually constitutive and not, as pointed out by Faludi above, nicely ordered boxed stacked upon boxes. The theorisation of place started to gain momentum during the $1980 \mathrm{~s}$ when it became apparent how exclusionist communities (and even nationalist rhetoric) could be coupled with the common-sense understanding of places as representative of uniform and singular identities-spaces of coherent and rooted communities with legacies stretching far back in history. Meanwhile, with the increase in urbanisation, globalisation and international migration, scholars began to critically address the underlying assumptions of such common sense place-imaginaries and to work through the notion with concern for greater socio-spatial variation, especially including marginalised and impoverished voices. One particularly prominent figure in these debates was Massey and it is her work that we shall draw on here because it fits well with the call for both contextsensitivity as well as structuring forces of power.

Massey argues how any identity of place is often contested, and any uniqueness of a place is not (necessarily) the result of some long internalised history. Rather, it is the momentary conjuncture of several identities and relations stretching across the individual place and being continually produced and reproduced (Massey, 1991). Second, a place is not easily defined by any administra- 
tive boundaries, as these are often arbitrary to the meanings and dynamics involved in its constitution, and third, and perhaps most challenging; a place is a process rather than a demarcated location on a map (Massey, 1991). Instead of imagining places as areas with boundaries, "they can be imagined as articulated moments in networks of social relations and understandings" (Massey, 1991, p. 28). When understood as a specific conjunction of relations, a specific combination of circumstances, she argues, it is also possible to comprehend how the global is present in the local and the local is present in the global, and how the instance we call place is constituted in the interaction between both. Finally, in further theorising the notion of process and instability she writes how places are spatio-temporal events (Massey, 2005). They are characterised by the simultaneity of process, flow and change together with the particularity and specificity of the "here and now'-a "throwntogetherness," she calls it (Massey, 2005, p. 140). Indeed, it is the very coming together of the here and now, and the inevitable negotiation they cause, that exactly characterises the nature of places:

What is special about place is precisely that throwntogetherness, the unavoidable challenge of negotiating a here-and-now (itself drawing on a history and geography of thens and theres); and a negotiation which must take place within and between both human and non-human. (Massey, 2005, p. 140)

This way of understanding place represents not only a change in how we see the role and influences of administrative boundaries, social communities and negotiations in the constitution of places; it also gives great importance to the aspect of temporality. Understood as conjunctures of relations being negotiated here and now, places are the result of overlapping relations at a certain moment in time. Thinking in these lines, we argue, it is possible to complement the discussion of the placebased approach above.

In aiming for more context and greater variation, the question, however, is where to begin and where to end. We argue that thinking in lines of conjunctures gives some points of orientation and that these are found within the notions of negotiation, articulation and legitimisation. As Massey emphasises the role temporality for the constitution of places we are provided with some directions as our analysis becomes sensitive both to the moment of study (the conjuncture could look different in the future) and to the nodes of negotiation. This orients our analytic lens towards points of negotiation either in the present and/or historically. The way we have worked with this is to search for the empirical testimonies of how the identified conjunctures are negotiated and contested, and what have been the driving forces in their being upheld. Secondly, our question echoes that of Clarke (2018, p. 201) as he asks of where the conjuncture takes place. As Clarke expresses it, the insistence on articula- tions is the key. In a short essay reflecting on earlier discussions with Massey, Clarke discusses the implications of multiple spatial relations when approached through conjunctural analysis. The conjuncture, he writes:

Articulates multiple spatial relations, such that politics come to play out on a terrain that combines and condenses multiple sites-the local (the deindustrialised city or region); the national, the regional (embodied in the EU, for example) and the global, whilst recognising that all of these are folded into one another. (Clarke, 2018, p. 205)

The recognition of how multiple sites, or territorial layers as we called them before, are interrelated and "folded into one another" is not new (e.g., Brenner, 2001, theorising scale). Many "dynamics are shared with other places" and "many lived experiences are common" (Clarke, 2018, p. 206) but it is through the specific forms of political articulation, as we read him, that the conjuncture takes distinctive spatial shapes. Adopting a conjunctural approach, therefore, does not erase the particular geography (returning to spatial blindness or 'placelessness') but it does prescribe that any spatial site that forms part of the articulation gets included in the analysis.

Finally, both Massey's and Clarke's thinking around conjunctural analysis is linked to economic geographies of neoliberalism. The reason this is relevant in this context is that it serves to show the third node of orientation that we find in the conjunctural approach-namely that of legitimisation. While conjunctures may be similar in different places, what contributes to making it locally specific is its interrelation to a political imaginary that act to legitimise the articulation of (particular) spatial interconnections (and not others). In our reading, this can be exemplified by the claim from Brenner and Theodore (2002) of how neoliberal policies are spatially selective and that we need to approach current neoliberal restructuring not as a homogenous tendency but as locally specific articulations of strategies and interconnections (see also Brenner \& Theodore, 2005). To the conjunctural approach, this means that the dominant economicpolitical backdrop forms part in sorting out and providing legitimisation of the particular articulation of the conjuncture. In order to approach how challenges to territorial cohesion unfold and are answered in the seven countries included in this cross-national research project, we need to look at how neoliberal localisation strategies become embedded within particular contexts characterised with institutional and regulatory path dependencies. In summary, we argue that a conjunctural analysis of territorial cohesion is concerned with conjunctures that form across neoliberal variegation and their resulting differentiation. Such conjunctures contain both answers to economic restructuring and the creation of locally specific strategies establishing interconnections between e.g., local development plans and their regional counterparts, networks between business clusters and 
local governments promoting corporate social responsibility, and community-led area-based programmes to fight localised expressions of social exclusion. Moreover, that both historically and context-dependent place identities and locally specific political imaginaries play crucial parts in how such strategies become articulated as moments of conjunctures. It is through the insistence on 'local' or 'place-based' articulations that we try to sort out how local cases both express local variegation and form part of particular conjunctures. All in all, the approach tries to work with this multiplicity to explore how the selected places provide reciprocal learnings among them and to deepen our understanding of their contextual influences.

\section{Case Study Methods}

As mentioned earlier, the case studies that are used as examples in this article are based on an on-going research project involving seven member countries of very different sizes and national characteristics. Selecting the three cases in each country was subject to much attention. Obviously, while cases might be similar concerning some parameters, they would differ on others, and instead of striving for the similarity of cases, a similar approach of two stages for selecting cases was adopted. First, a region was selected for each country, and as the research focuses on multi-level governance policies, it was central that the local cases were selected with a focus on their interaction with the surrounding region. Second, within the region, three case-areas were selected at an urban, a suburban and a rural locality. In some partner countries, these localities constitute their own municipal and local government unit, while in others the localities refer to a conglomerate of municipalities. The research aims to analyse the approach to territorial cohesion, inequality and urbanisation in each of the different cases, and to understand how and why approaches differ, what they share and what the consequences of these differences and similarities in approaches might be.

The cases were selected based on common criteria. The urban cases were to be centres of a mono-centric agglomeration; classified as metropolis or, for the smaller countries of Denmark and Lithuania, a large city in the ESPON 2007 study. Huge metropolitan cities were avoided, as they would not have similar counterparts in some of the other countries. The suburban cases were to be characterised, as far as possible, by a recent experience of population growth related to suburbanisation and/or urban sprawl, significant commuting to the core city of the agglomeration, the domination of nonagriculture functions, internal diversification and a presence of social challenges. Finally, the rural cases were to be characterised by low population density, a tendency for outmigration and a central role of agriculture.

The methods employed were policy analysis and keyinformant interviews. In each case, key policy documents reflecting the policy areas of economic growth, urban regeneration, childcare, active labour market policy and vocational educational training were identified and analysed with regard for their main discourses. Secondly, in each case, interviews with approx. 25 key-informants reflecting a spread between community, governance and business actors were conducted. In supplement, another 5 key-informant interviews per country were conducted with actors at regional and national levels to explore the links between different governance levels further.

The selection of cases can be called informationoriented' (Flyvbjerg, 2006) aiming for maximum variation between rural, suburban and urban cases within the region/or functional region. The case study methodology follows Yin (2003), where it is defined as an empirical inquiry that "investigates a contemporary phenomenon within its real-life-context, especially when the boundaries between phenomenon and context are not clearly evident" (Yin, 2003, p. 13). To this end, a case study will "have to cover both the phenomenon of interest and its context, yielding a large number of potentially relevant variables" (Yin, 2003, p. 48). Through this type of case study, it is possible to explore the influence and significance of the variables as contextualised rather than isolated in the analytical framework-what the variable means, so to speak, in its situated and specific context.

\section{Conjunctures of Knowledge-Economy, Economic Growth and Inequality in Aarhus, Milano and Vienna}

In the first example, the empirical cases compared are Vienna, Milan and Aarhus (for in-depth analysis, see Boczy, Cefalo, Parma, \& Nielsen, 2020). In terms of, for example, population size as well as position and importance in a national and a European context, these three urban cases differ substantially. However, the dynamics of their interplay between economic growth and inequality in the context of the knowledge economy shows interesting and relevant characteristics between them.

Vienna is the business, educational, research and cultural hub of Austria. It is the capital city and a 'doorway to the East' of Europe. The city has 1.8 million inhabitants and is both a municipality and a federal state. Milan is located in the Northern part of Italy and has 1.4 million inhabitants. It is the leading Italian industrial city and the main economic and financial centre of Northern Italy. The city is colloquially described as the "bridge' between Italy and the world" and it is associated with fashion, design and culture. Aarhus is the second biggest city in Denmark with a population of 350,000 inhabitants. It is the centre and growth motor of its region. For all three cities, internationalisation and the development of the knowledge economy are cornerstones in their strategies for economic growth. However, the position for realising this and the approach for doing so differ.

All three cities strive to support the development of the knowledge economy. However, they differ as to the approach to their industrial and manufacturing past. 
In Vienna, the focus is on the development of new knowledge and innovative high-tech products based on three interlinked pillars: universities, high-tech production and knowledge-intensive services (Municipal Department 18, 2014). Industries have, to some extent, relocated to outside the cities; even if efforts are now made to reserve land for returning industry. In Aarhus, the knowledge economy is to be supported through the development of strategic business clusters but coupled with an explicit aim to retain industry-heavy businesses as part of the business landscape; located in suitable places in an attempt to future-proof the city through a broad economic profile. In Milan, the focus is on developing strategic clusters and supporting innovative entrepreneurship, in particular, knowledge-intensive start-ups; both of which are to be in "synergy with the university system, research centres, the cultural world and the Third Sector" (Commune di Milano, 2016, p. 7). At the same time, however, the manufacturing tradition is still strong and the political aim is to sustain and develop it further. The manufacturing sector is to be reformed to become highly specialised, highly qualified, innovative and environmentally and socially sustainable. The sector is to be a driver for the economy as a whole and to link with, build on and support the knowledge economy. Thus, while the cities have a focus on the knowledge economy in common, their approach to industry differs.

In all of the cities, education is described as the backbone of the knowledge economy. Thus, in Vienna, a key focus is ensuring that residents can meet the educational requirements of a city centred on the knowledge economy. However, while tertiary education is needed for the knowledge economy, there is a lack of resources for this and a lack of qualified workers, which points to a mismatch between the supply and demand of the knowledge-intensive labour market. Turning to Aarhus, the aim is for the city to consolidate its position in the knowledge-based part of the global value chain with education as a cornerstone (Aarhus Municipality, 2015); offering a highly-skilled workforce to businesses located in Aarhus. This latter goal seems to be realised as Aarhus educates more highly-educated individuals than they have workplaces for. In Milan, the focus on university education is less strong; possibly due to a national Italian context, still marked by comparatively low-qualified and less-innovative supply of jobs. All three cities are educational hubs in a national context and thus contribute to the development of the knowledge economy at a national level by providing the education necessary for a highlyskilled workforce. Along with their national importance, the cities strive to position themselves in an international context. Their positions differ, however. As described, Vienna has a clear international position already, Milan to some extent as well, while Aarhus, as the smallest of the three, holds a less-prominent position internationally. Nevertheless, the aim is for Aarhus to develop into "a national growth-centre with international impact" (Aarhus Municipality, 2017, p. 4). For all three cities, it seems that being a national centre is not sufficient to thrive in the knowledge economy.

The rise of the knowledge economy entails a risk of growing-inequality (Cucca \& Ranci, 2016) as some groups and some areas can adapt to the knowledge economy and benefit from it while others are not. This is addressed to a varying extent in the three cities. It is most explicitly addressed in Milan where there is a focus on aiding the peripheral areas in benefitting from economic development. Economic growth is described as supporting social cohesion through creating new job opportunities within manufacturing but at the same time, it is acknowledged that there is a potential risk of Milan developing as a 'two-speed city' were certain parts profit from economic growth, the knowledge economy and internationalisation while other parts, the disadvantaged, peripheral areas, get left behind. In Vienna, social inclusion efforts centre on infrastructure and equal access, for example, to education and health facilities focusing on education and re-training to help low-educated youths and adults enter the labour market. Provision of childcare is presented as important for social mobility and for reducing gender inequality. Territorial inequality is not addressed. Finally, in Aarhus, the potential downsides of globalisation, internationalisation and economic growth are not in focus. Economic growth is described as a motor for the development of the city and the region and globalisation as 'a train on the move' that one cannot afford to be late for. There is a focus on distributing growth spatially to secure that all areas of the city benefit from it, not least the disadvantaged areas. However, growth is described as beneficial for everyone if planned for in the right way, as a tool for changing the situation of the deprived areas and as the basis for increasing municipal investments, leading to new offers and service solutions for the most deprived. Territorial inequality is thus addressed, but economic growth is seen as a solution to rather than a potential cause for inequality.

Through these analyses, it was possible to gain further insight into how the mutual conjuncture around articulations of taking part in the knowledge economy has been shaped in the three cases, how it is intermeshed with considerations of how consequences of economic growth impact social inequality and the different ways in which these consequences are, or are not, addressed. The variegated transition to the knowledge economy (Brenner, Peck, \& Theodore, 2010) in the three cases form around local articulations of the conjuncture's interrelations with culture, tradition, industrial patterns and territorial concentrations of social inequality. Milan's history as a manufacturing city, and to some extent Aarhus's as well, is still present and have become part of a dual strategy to combine the knowledge economy with the local industries to broaden the city's profile. In all three cities, education is a cornerstone. However, the ambition of being an educational hub seems to be best realised in Aarhus, while Vienna is challenged in resources for higher education and a mismatch between 
demand and supply. The risks entailed in economic growth in terms of rising territorial inequality are explicitly addressed in Milan. In Vienna, territorial inequality is not addressed at all. In Aarhus, it is addressed, but not as a consequence of economic growth. To the contrary, in Aarhus, economic growth is seen as a solution to territorial inequality. Whether Aarhus succeeds in distributing growth across the city, remains to be seen.

\section{Conjunctures of Identity, Entrepreneurialism and Government Relations in Legnano and Horsens}

The second example focuses on two suburban cases from the COHSMO project, namely Legnano, in Italy (Cordini, Pacchi, \& Parma, in press), and Horsens, in Denmark (Fallov, Jørgensen, Nielsen, \& de Neergaard, in press). In both cases, a widespread sense of place-identity plays a significant role in sustaining their local development and economic restructuring. This makes them good examples of the need to analyse particular conjunctions of changing identity, entrepreneurial spirit and connections to formal, local government. Both cities are adjusting to deindustrialisation and changing economic structures. In both places, there are strong alliances among businesses, which play a significant role in local development and in securing labour market inclusion in some very particular place-specific versions of corporate social responsibility. Thus, as pointed with Clarke above, economic restructuring and development are closely interwoven with political imaginaries and particular historical and place-specific identities.

Horsens Municipality has about 90.000 inhabitants and is located centrally in Jutland, along the East coast, near other big cities such as Aarhus, Vejle and Silkeborg. It is easy to live in Horsens and work in any of the nearby big cities. As housing prices are low and commuting is easy, this has led to current population growth. Meanwhile, Horsens is struggling with its history as a rough blue-collar town that used to house one of the largest prisons in Denmark. The municipality is relatively poor and lacks the big family industries that traditionally have brought in the substantial tax revenues to a city this size. The main narrative of Horsens is thus centred on attempting to change the image of Horsens from being primarily an industrial town with low educational attainment to an educational and cultural town that benefits not only from its infrastructural location near major motorways, but also from its lively cultural life supported by voluntary activity. The Horsens Alliance, formed in 2013, holds a central position in the development of Horsens. The alliance consists of members of municipal departments within the labour market, education and social services, union representatives and local business actors. The alliance is a key factor in the territorial development of Horsens as it unites different interests, pools local resources and makes it possible to drive the development of Horsens forward despite a tight economic budget. The alliance has played a crucial part in the rebranding of Horsens during the last 20 years and works, amongst other things, for job creation and raising educational attainment (Fallov et al., in press).

Legnano has around 60.000 inhabitants and is strategically located 20 kilometres North-West of Milan between the metropolitan core and an important axis that connects it with Switzerland and Northern Europe. Legnano has long been an industrial city and is trying to recover from deindustrialisation. Besides the consequent loss of jobs, it has also had substantial effects on mobility with increased commuting to the main city, Milan, and long-term outmigration. Also, the qualification level of the workforce has decreased. Presently, there seems to be a relocation of high-skilled workers and the most qualified young people towards Milan, while those migrating into the city tend to be lowskilled workers. The main strengths of Legnano are its entrepreneurial potential, rooted in its industrial tradition, the overall wealth and good quality of life. Despite the substantial deindustrialisation process and the economic crisis in 2008 , there are still productive specialisations relating to the textile industry (shoemaking among others). Based on its history, Legnano appears to have a stable and long-standing sense of industrial identity. Although deindustrialisation and the financial crisis have changed the local industrial fabric, there is an entrepreneurial spirit to Legnano and its inhabitants (Cordini et al., in press).

Both places have a strong and lively civil society based on a long-standing collaboration with local municipal actors. Moreover, in both places, business networks have a key role in supporting civil society organisationsespecially sports organisations. In Horsens, the business network has been instrumental in turning the historical centre, shaped by the old prison, into a cultural event centre. Similarly, in Legnano, business networks play a key role in sustaining a historical tournament, which is a focal point for the general sense of local, place identity. What appears to be different between the two is the degree of formality and coordination involved in the collaboration between business networks and local public actors. The Horsens Alliance is formalised with economic interdependent relations to the local municipality. Thus, the Horsens Alliance is closely involved in developing labour market strategies (formalised CSR and social investment strategies). In contrast, while the business networks in Legnano have a long historical tradition, they seem to be more directed towards establishing industrial clusters than they do towards public services and the level of formalisation appears to be significantly lower.

A critical similarity between the two places is how the close interdependent relations between business alliances and local government (however formalised or not) represent a possible democratic gap. As the coalitions are serving the interest of economic growth while also being the key drivers in the discourse of a strong local place identity, they leave little room for any alternative voices. Meanwhile, there are also signs of how 
the coalitions will take on social and democratic responsibilities. Indeed, in Horsens, the dominating discourse of the local place identity is coupled with the notion of 'lifting together.' This denotes the importance of corporate responsibility for equity and inclusion in development strategies. Potentially, some similar tendencies may be witnessed in Legnano, even if the discourse is presently more reactive than proactive:

As it always happens when some historical, symbolic event is put at the centre of public discourses around identity, there is a risk of over-representation of its importance of identity, and that such identity discourse shows, in fact, a picture of Legnano that lies mainly in the past and looks backwards, with a risk of a regressive, rather than a progressive attitude towards identity discourses. (Cordini et al., in press, p. 80)

With a conjunctural analysis, we focus on the dynamics that Legnano and Horsens have in common, despite differences in their particular history, national and regional contexts. By taking this perspective, other dynamics emerge. In this example, it is the particular articulations of entrepreneurial culture, networks of businesses and local government and their interactions with local, place identity. While discourses of place-identity drawing on the particular history of place become a nodal point for the networks in both cities, they vary in character and reactiveness. These articulations have different effects on territorial cohesion and patterns of inequality; thus, the conjunctures vary in their capacity to shield against uneven development and their concern with future equity of the cities. This shielding capacity of particular cities and neighbourhoods is conceptualised by Sampson as 'collective efficacy' (Sampson, 2001, 2011, 2012). As Sampson argues, the concept of collective efficacy can be a composite measure of the interaction between location, place attachment, social infrastructures, and degree of networks to local decisionmakers. Even though both Horsens and Legnano can be characterised as having dense social infrastructures and place identities and entrepreneurial cultures that can be mobilised in legitimising local development strategies, these elements are articulated differently in the two places. The two localities have different types of collective efficacy which have variegated results for territorial cohesion.

\section{Concluding Discussion}

In this article, we have begun the work of developing a conjunctural analytical framework for researching the complex dynamics of territorial cohesion and territorial inequality in a way that takes the place-based approach in EU development policies seriously. As outlined in the introduction, a place-based approach was needed for EU cohesion policy to better handle territorial inequality and to consider the specific ways social and economic dimensions interact and the role multi-level governance plays in promoting change, securing services and mobilising assets. Although the place-based approach to territorial cohesion has spread (Faludi, 2016), there remains a need for providing systematic accounts on how the interaction between the territorial mobilisation of capital and multi-level governance processes generate possibilities for development. The policy discourse on territorial cohesion thus highlights the relevance of developing the conceptual understanding of how relations between inequality, urbanisation and territorial cohesion play out in their place-bound and contextual variation.

Thinking in terms of conjunctural analysis is a way to operationalise a research method in a way that takes the complexity of these interactions into account. We suggest that with such a perspective, it is possible to draw out dynamics from the empirical material representing diverse voices from varied places that would otherwise remain hidden. As outlined above, we have operationalised conjunctures as the present time formation of articulations of place-identities, political strategies, networks, organisations and forms of collective action, which arrived from the analysis of policy documents and key-informant interviews. In the analysis of the empirical examples, we have paid particular attention to the interplay between local discourses and their formation in and through their particular contexts. We have paraphrased Massey in a way where we have taken the 'throwntogetherness' at face value and let different variables enter the analysis of what we consider present conjunctures of the places in question (and with regard for the scope of our research). The first example outlines how complex conjunctures of interacting dynamics of discourses of economic growth through the development of the knowledge economy, coupled with particular interactions between public and private sectors, and industrial patterns shape different paths in the cities of Milan, Aarhus and Vienna. The second example, the comparison of Legnano and Horsens, shows that the collective organisation of business interests and their independent relation to the local government take varying paths in the two cities. In Horsens and Legnano, historical place identity defines varied path dependencies for new development shaped by the context-dependent balancing, interaction and formalisation of public and private interests and responsibilities.

A conjunctural analysis, we suggest, is a supplement to conventional methods of comparing cases. We have argued that much conventional comparison is mainly based on 'similar' cases (e.g., on cases that can be predefined with respect to key characteristics). A conjunctural analysis, in contrast, allows for analysis of more diverse cases, allowing the analysis to involve more variables or seeming differences, e.g., the 'throwntogetherness,' and comparing them through a more thematic shared theme (or shared similarities in key dynamics concerning the research focus) to learn about the given 
theme as it unfolds in the different case contexts. As such, a conjunctural analysis aims to gain a deeper understanding of articulations of dynamics and how they generate learning about common themes and tendencies and their unfolding in different settings, which again might tell us more about the general processes behind them. With this approach, we can understand more about how such processes unfold and affect different localities than if we had selected similar cases within and across countries. We simply get a wider understanding through more examples from different cases, and we get more suggestions for possible room for manoeuvre of policy in supporting, generating and underscoring development from above and below.

A conjunctural analysis, we would argue, provides insights into the forces, factors and interplay of different actors that become significant in the particular context. By focusing on the interplay of forces and factors in the three cities of Milan, Aarhus and Vienna we learn more about the particular patterns of territorial inequality than if we had focused solely on economic growth strategies or similarities in labour shortage. Similarly, when considering the differences and similarities between the conjunctures in Horsens and Legnano, we gain a promising insight into the multiple ways that organisational structures and policy discourses interact with place identities that form in response to history and through relations to other places and other scales. However, the present outline is merely the beginning of developing the conjunctural analysis as an approach to better understand the dynamics involved when researching cohesion policy and what cohesion 'does' (Abrahams, 2014; Atkinson \& Zimmermann, 2018) and for whom.

Conjunctural analysis helps to understand how different territorial layers become interlocked with economic and political strategies for economic restructuring and local development, whether it be to support a position in the knowledge economy or sustain post-industrial development and entrepreneurial culture.

The central argument of this article is that places are multiple and diverse and that we need an analytical perspective which is better attuned to grapple with similar articulations across a diverse variety. The conjuncture is a differentiated and context-sensitive construct, a variable factor, but one that is tied to locally-defined and-experienced social relatedness to place. Thinking through conjunctures is a contribution to the European debate on territorial cohesion as it highlights the complex interconnections and articulations of political imaginaries, regulatory path dependencies, local responses to forces of urbanisation and local mobilisation of place-based assets. Interconnections and articulations which exist between formal and informal networks and between scalar relations of governments and local stakeholders, and in response to which it is necessary to theorise and reflect on one's analytic approach in order to understand contemporary challenges to and local strategies to develop territorial cohesion.

\section{Acknowledgments}

The authors are grateful to the reviewers for their constructive comments.

\section{Conflict of Interests}

The authors declare no conflict of interests.

\section{References}

Abrahams, G. (2014). What "is" territorial cohesion? What does it "do"? Essentialist versus pragmatic approaches to using concepts. European Planning Studies, 22(10), 2134-2155.

Aarhus Municipality. (2015). Klog vækst frem mod 2050-Planstrategi 2015 [Smart growth towards 2050-Planning strategy 2015]. Aarhus: Aarhus Municipality.

Aarhus Municipality. (2017). Erhvervsplan 2018-2029. Overblik [Buisinessplan 2018-2019. An overview]. Aarhus: Aarhus Municipality.

Atkinson, R., \& Zimmerman, K. (2018). European spatial planning policy. In H. Heinelt \& S. Münch (Eds.), Handbook of European policy: Interpretive approaches to the EU (pp. 156-172). Cheltenham: Edward Elgar.

Barca, F. (2009). Agenda for a reformed cohesion policy. Brussels: European Communities.

Barca, F., McCann, P., \& Rodríguez-Pose, A. (2012). The case for regional development intervention: Place-based versus place-neutral approaches. Journal of Regional Science, 52(1), 134-152.

Boczy, T., Cefalo, R., Parma, A., \& Nielsen, R. S. (2020). Positioning the urban in the global knowledge economy: Increasing competitiveness or inequality. Social Inclusion, 8(4), 194-207.

Böhme, K., Doucet, P., Komornicki, T., Zaucha, J., \& Świątek, D. (2011). How to strengthen the territorial dimension of 'Europe 2020' and the EU Cohesion Policy. Warsaw: Ministry of Regional Development.

Brenner, N. (2001). The limits to scale? Methodological reflections on scalar structuration. Progress in Human Geography, 25(4), 591-614.

Brenner, N., Peck, J., \& Theodore, N. (2010). After neoliberalization? Globalizations, 7(3), 327-345.

Brenner, N., \& Theodore, N. (2002). Cities and the geographies of "actually existing neoliberalism." Antipode, 34(3), 349-379.

Brenner, N., \& Theodore, N. (2005). Neoliberalism and the urban condition. City, 9(1), 101-107.

Clarke, J. (2018). Finding place in the conjuncture: A dialogue with Doreen. In M. Werner, J. Peck, R. Lave, \& B. Christophers (Eds.), Doreen Massey-Critical dialogues (pp. 201-213). London: Agenda Publishing.

Commune di Milano. (2016). Programmatic lines related to the projects and actions to be carried out during the mandate. Milan: Commune di Milano. 
Cooke, P. (1990). Back to the future: Modernity, postmodernity and locality. London: Unwin Hyman.

Cordini, M., Pacchi, C., \& Parma, A. (in press). Report on policy analysis (COHSMO Working Paper No. D4.6 Italy). Milan: Polytechnic University of Milan.

Cucca, R., \& Ranci, C. (Eds.). (2016). Unequal cities: The challenge of post-industrial transition in times of austerity. Abingdon: Taylor \& Francis.

Fallov, M. A., Jørgensen, A., Nielsen, R. S., \& de Neergaard, M. (in press). Report on policy analysis (COHSMO Working Paper No. D4.6 Denmark). Copenhagen: Aalborg University.

Faludi, A. (2006). From European spatial development to territorial cohesion policy. Regional Studies, 40(6), 667-678.

Faludi, A. (2016). The poverty of territorialism: Revisiting European spatial planning. disP-the Planning Review, 52(3), 73-81.

Flyvbjerg, B. (2006). Five misunderstandings about casestudy research. Qualitative Inquiry, 12(2), 219-245.

Jones, M., \& Woods, M. (2013). New localities. Regional Studies, 47(1), 29-42.

Massey, D. (1991). A progressive sense of place. Marxism Today, 24-29.
Massey, D. (2005). For space. London: Sage.

Municipal Department 18. (2014). Urban development plan Vienna 2025. Vienna: Municipal Department 18-Urban Development and Planning, Retrieved from http://media.obvsg.at/AC12378320-2001

Sampson, R. J. (2001). How do communities undergird or undermine human development? Relevant contexts and social mechanisms. In A. Booth \& A. C. Crouter (Eds.), Does it take a village? Community effects on children, adolescents, and families (pp. 3-28). Mahwah, NJ: Lawrence Erlbaum Associates Publishers.

Sampson, R. J. (2011). Neighborhood effects, causal mechanisms and the social structure of the city. In P. Demeulenaere (Ed.), Analytical sociology and social mechanisms (pp. 227-249). New York, NY: Cambridge University Press.

Sampson, R. J. (2012). Great American city: Chicago and the enduring neighborhood effect. Chicago, IL: University of Chicago Press.

Savage, M., \& Duncan, S. (1990). Space, scale and locality: A reply to Cooke and Warde. Antipode, 22(1), 67-72.

Yin, R. (2003). Case study research: Design and methods (3rd ed.). Thousand Oaks, CA: Sage Publications.

\section{About the Authors}

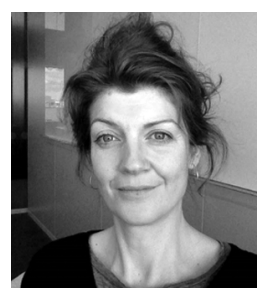

Maja de Neergaard (PhD) is a Researcher at the Department of the Built Environment, Aalborg University, Denmark. Her research interests are urban geography and culture, urban/regional restructuring processes, inhabitation practices, and theory of the relations between humans, nature and technology. Presently, she is working on the Horizon 2020 project "Inequality, Urbanization and Territorial Cohesion: Developing the European Social Model of Economic Growth and Democratic Capacity" (COHSMO).

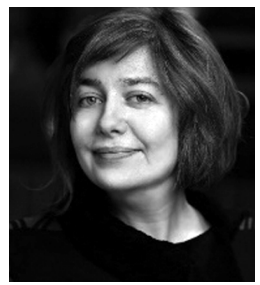

Mia Arp Fallov (PhD Sociology) is Associate Professor of Social Integration and Social Policy Strategies, Department of Sociology and Social Work, Aalborg University, Denmark. Her research covers territorial cohesion, urban planning welfare policy, urban sociology, social theory and strategies to improve inclusion. Recently, she has been working on the EU Horizon 2020 project "Inequality, Urbanization and Territorial Cohesion: Developing the European Social Model of Economic Growth and Democratic Capacity" (COHSMO).

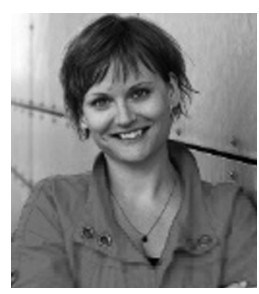

Rikke Skovgaard Nielsen is a Senior Researcher of Department of the Built Environment, Aalborg University, Denmark, and coordinates the Master Program "City, Housing and Settlement Patterns." Rikke's research is centred on inequality, deprived neighbourhoods, diversity, segregation and regeneration plans. Of major international research projects, she has taken part in the NORFACE project NODES, the EU FP7 project DIVERCITIES and currently the Horizon 2020 project COHSMO. Recent publications include Governance Arrangements Targeting Diversity in Europe: How New Public Management Impacts Working with Social Cohesion (https://doi.org/10.1080/02723638.2018.1511190).

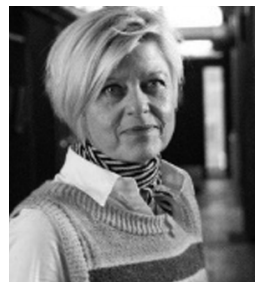

Anja Jørgensen (PhD) is Professor of Urban Sociology and Head of the research group SocMap (www.socmap.aau.dk) at the Department of Sociology and Social Work, Aalborg University, Denmark. She has conducted a wide range of research projects within urban sociology, territorial cohesion, local communities and local social integration. Recently she has been working on the EU Horizon 2020 project "Inequality, Urbanization and Territorial Cohesion: Developing the European Social Model of Economic Growth and Democratic Capacity" (COHSMO). 